\title{
LA PRIVATIZACIÓN DE LA SALUD El caso de la industria farmacéutica
}

\author{
GUILLERMO FOLADORI
}

Universidad Autónoma de Zacatecas. México

\author{
PALABRAS CLAVE ADICIONALES \\ ADDITIONAL KEYWORDS \\ $\begin{array}{ll}\text { Salud pública, Enfermedades infecciosas, } & \text { Public Health, Infectious Diseases, Public- } \\ \text { Asociaciones público-privado. } & \text { Private Partnerships. }\end{array}$ \\ Asociaciones público-privado.
}

RESUMEN. El nuevo milenio muestra una aparente paradoja. La intensificación del proceso de globalización que, según los voceros de los organismos internacionales, constituye el camino para que los países pobres salgan de su atraso histórico, y el resurgimiento y profundización de enfermedades infecciosas, que colocan a muchos de los paises pobres en situación catastrófica, viendo su población diezmada y reducida la esperanza de vida a niveles medievales. Esa paradoja ha cristalizado en una crisis del sistema de producción mercantil de medicamentos. Los actores son las empresas farmacéuticas transnacionales y las organizaciones que defienden los intereses de los enfermos. En este artículo pretendemos hacer una revisión de esta crisis de la salud a nivel mundial. También mostraremos las dos tendencias que se manifiestan. Por un lado, la privatización de la salud pública a través de las asociaciones público-privado (Private-Public Partnerships-PPP), y por otro, una mayor autonomía de los países en la satisfacción de sus necesidades a través de la salud pública y en contra de las tendencias impuestas por las instituciones internacionales.

ABSTRACT. The turn of the millennium reveals an apparent paradox: the intensification of the globalization process, which, according to spokesmen from international organizations, constitutes a sure path for poor countries to overcome their historical socio-economic deprivation, and the resurgence of several infectious diseases, which place many countries in a catastrophic situation characterized by declining populations and medieval life expectancy levels. This paradox is reflected in the crisis of medicine production by the market. The major actors are the transnational pharmaceutical companies and the organizations that defend patien' interests. In this article, Iwill review the health crisis on an international level, and discuss two trends which are emerging; first, the privatization of the world public health system, through Private-Public-Parterships (PPPs); and, second, greater autonomy of countries in the satisfaction of their needs through public health and against the pressure imposed by international institutions.

E-mail: fola@cantera.reduaz.mx

\section{Revista Internacional de Sociología (RIS)}

Tercera Época, $n^{\circ}$ 34, Enero-Abril, pp. 33-64, 2003. 
RIS

REVISTA INTERNACIONAL DE SOCIOLOGIA

№ 34, Enero - Abril, 2003

GULLLERMO FOLADOR

\section{INTRODUCCIÓN}

La última década del siglo XX y los primeros años del siglo XXI muestran una aparente paradoja. Por un lado, la profundización de un proceso de globalización que, según los voceros de los organismos internacionales como el Banco Mundial, el Fondo Monetario Internacional, la Organización Internacional del Comercio o la Organización Mundial de la Salud, constituye el camino cierto para que los países pobres salgan de su atraso histórico. Por otro lado, el resurgimiento y profundización de las enfermedades infecciosas, que colocan a muchos de los países pobres en situación catastrófica, ya que están viendo que su población queda diezmada y reducida la esperanza de vida a niveles medievales.

Esa aparente paradoja ha cristalizado en una crisis del sistema de producción mercantil de medicamentos. Los actores son las empresas farmacéuticas transnacionales, por un lado, y las organizaciones que defienden los intereses de los enfermos, por otro. Algunas veces los intereses de estos grupos se expresan en posiciones de países o de organizaciones internacionales. Pero resulta evidente que la salud se ha convertido, en la última década, en uno de los espacios más claros de expresión de las luchas sociales.

En este artículo pretendemos hacer una revisión de esta crisis de la salud a nivel mundial y mostrar las tendencias que se vislumbran.

\section{EL ERROR DE LA HIPÓTESIS DE LA TRANSICIÓN EPIDEMIOLÓGICA}

En los últimos cincuenta años la esperanza de vida en los países de menores ingresos ha pasado de 44 a 64 años. Pero debido a pandemias como el SIDA, la tuberculosis y otras enfermedades infecciosas, este logro se puede revertir en pocos años en muchos países, y retroceder a niveles incluso inferiores. En el África sub-Sahariana se estima que la esperanza de vida caerá de 62 a 43 años (Geffen, 2001). En Mozambique la esperanza de vida para el 2010 estará en torno a los 36 años (GFRH, 2002). En las últimas décadas la humanidad ha visto el rápido avance de la integración económica y social, pero también de las enfermedades infecciosas. Algunas de estas enfermedades son "emergentes" en el sentido de recién conocidas, como el SIDA y la fiebre púrpura brasileña, otras son viejas conocidas que se expanden, como el hantavirus, el dengue o la fiebre de Ebola. Otras, por último, son resultado de cambios en los propios microbios - no sin la presión antrópica sobre el ecosistema - como la tuberculosis resistente a las multidrogas (Farmer, 1996).

Durante la segunda mitad del siglo XX los países desarrollados experimentaron la llamada transición epidemiológica, donde las enfermedades infecciosas dejaron de ser causas importantes de muerte y tomaron su lugar las enfermedades cardio- 
vasculares y el cáncer. ${ }^{1}$ Acompañando ese proceso, las investigaciones biomédicas centradas en los países desarrollados se fueron especializando en el cáncer, las enfermedades circulatorias y de la piel, y otras enfermedades de los países ricos (Lewontin y Levins, 1996). Entre tanto, en los países pobres las enfermedades infecciosas seguían teniendo un papel importante en las causas de mortalidad, a pesar de que en algunos de ellos el cáncer y las enfermedades del corazón pasaron a ser las principales causas de muerte. Brasil es un ejemplo típico de ese híbrido, y en 2001 las causas de muerte por problemas del aparato circulatorio fueron el $32 \%$ del total, mientras las enfermedades infecciosas alcanzaban el $6 \%$ (RIPSA, 2002).

Pero si algunos pensaban que los países desarrollados ya habían superado la fase de las enfermedades infecciosas y los países pobres las estaban superando se equivocaron, por varios motivos. En primer lugar, porque las enfermedades infecciosas no reconocen barreras políticas o de países, de manera que su inexistencia en países desarrollados no garantiza su inmunidad mientras exista en los países pobres. El caso mas notorio es el SIDA, pero otras enfermedades infecciosas se están agudizando, como la fiebre del Nilo, que sumó 216 muertes en 2002 en los EEUU ${ }^{2}$, o los 403.000 casos de enfermos de criptosporidiasis en Milwaukee en 1993; la enfermedad del legionario y otras (CDC, 2002). A esto hay que agregar la posibilidad de la introducción premeditada de enfermedades infecciosas en determinados países como mecanismo de sabotaje o guerra. Ya en 1951, durante la Guerra de Corea, los Estados nidos crearon el Servicio de Inteligencia de Epidemias como mecanismo de prevención, frente a esa posibilidad. En la actualidad, el gobierno de los Estados nidos está planeando vacunar a toda su población contra la viruela en el correr de los próximos dos años, frente a la posibilidad de una acción terrorista (Connolly, 2002). Sea por el flujo diario de animales y personas, o sea de forma premeditada, el hecho es que la inexistencia de una enfermedad infecciosa en un país no garantiza su inmunidad en los demás, a menos que las condiciones ecológicas lo impidan, y éstas también pueden cambiar como lo indica el calentamiento global ${ }^{3}$.

En segundo lugar, porque las enfermedades están asociadas a la pobreza, y no es claro que el crecimiento económico de las últimas décadas haya tenido como

\footnotetext{
${ }^{1}$ El concepto de transición epidemiológica esconde el hecho de que dentro de esos países desa-rrollados las clases pobres continúan sufriendo otro tipo de enfermedades (Farmer, 1996), o experimentando nuevas enfermedades poco investigadas, como ocure con la obesidad en los Estados Unidos (Townsend, et al., 2002).

${ }^{2}$ También murieron miles de animales silvestres, docenas de especies exóticas de los zoológicos, y posiblemente extensas cantidades de aves de granja (Weiss, 2002).

${ }^{3}$ Según el Panel Intergubernamental del Cambio Climático y la Organización Mundial de la Salud el calentamiento global podría provocar la expansión de enfermedades transmitidas entre personas por la picada de insectos, como la malaria, encefalitis y fiebre amarilla (Theo; Dana, 1998).
} 
RIS

REVISTA INTERNACIONAL DE SOCIOLOCIA

№ 34, Enero - Abril, 2003

GUILLERMO FOLADORI

contraparte una mayor igualdad en la distribución del ingreso ${ }^{4}$. Varios estudios sobre la relación entre pobreza, estatus social y enfermedad muestran una correlación compleja pero constante entre ellos. Evans et al. (1994) muestran que no sólo la pobreza está asociada a las enfermedades, también la salud de una población es correlativa de una mejor distribución del ingreso - en lugar de un aumento de su promedio como la mayoría de las estadísticas la miden-; y también muestran que el espíritu de progreso derivado de un periodo de desarrollo económico y mejor posicionamiento de una sociedad frente a otras es definitivo en mejorar la esperanza de vida de dicha población. Y aun muestran que en condiciones de pobreza una enfermedad puede llenar el espacio de otra previamente erradicada, lo que levanta la inquietud sobre las políticas unilaterales que combaten algunas enfermedades de manera específica sin atender al contexto socio-económico. En los Estados Unidos, Auerbach \& Krimgold (2001) muestran que esa correlación entre pobreza y enfermedad también está presente hoy en día en ese país ${ }^{5}$. Es evidente que el aumento de la pobreza y la desigualdad en el mundo o, en el mejor de los casos - como sostiene el Banco Mundial-, la cantidad constante de pobres en la última década (1.200 millones), junto a la expansión de las epidemias, no puede constituir una esperanza para grandes masas de población que viven en los países del Tercer Mundo.

También es indicativo de esta correlación entre pobreza, inequidad y enfermedad el hecho de que, en muchos casos, el aumento del nivel de vida reduce significativamente las enfermedades aun sin políticas de salud dirigidas. Las investigaciones de McKeown sobre las enfermedades en los siglos XVIII y XIX indican, por ejemplo, que las principales enfermedades infecciosas en Europa y Estados Unidos se redujeron varias décadas antes de la introducción de las vacunas y los antibióticos, como resultado del aumento del nivel de vida (Tesh, 1996). La tuberculosis, por ejemplo, siendo la principal causa de muerte entre los jóvenes adultos declinó considerablemente en los países industrializados aún antes del descubrimiento en 1943 de la streptomycina para combatirla, y posiblemente como resultado de la mejora general en el nivel de vida de la población; o el caso de la malaria en los Estados Unidos, que era epidémica en el siglo XIX y disminuyó en el siglo siguiente no como resultado de políticas de salud específicas, sino por cambios en la estructura económica y de ocupación del suelo (Farmer, 1996).

\footnotetext{
${ }^{4} \mathrm{~A}$ pesar de que el Banco Mundial informa de que la pobreza se estancó en términos absolutos en los últimos diez años, y que esto sería un resultado favorable de la globalización, otros estudios muestran que la metodología utilizada por el Banco Mundial, basada en promedios por países, oculta la desigualdad generada dentro de los países, y sostienen que en su conjunto la desigualdad creció, en lugar de disminuir (Wade, 2001).

5 "desigualdad de ingreso y nivel socioeconómicos son los factores más significativos que afectan a la salud también en este país" (Apud, GFRH, 2002).
} 
En tercer lugar, porque las enfermedades infecciosas requieren de un sistema de vigilancia, previsión y asistencia permanente. Durante las décadas del ochenta y noventa del siglo XX la crisis económica, las guerras y equivocadas políticas de salud, tanto de la Organización Mundial de la Salud como de muchos gobiernos, llevaron a un desmantelamiento de los sistemas nacionales de salud en muchos países y al consecuente resurgimiento de enfermedades previamente controladas. En 1990 la UNICEF declaraba que el 80\% de los niños del mundo estaban inmunizados contra las seis principales enfermedades (difteria, tétano, tosferina, polio, tuberculosis y sarampión). Una década después la cobertura cayó al $75 \%$, y en 19 países de África esa caída llegó a menos del $50 \%$. En Nigeria, por ejemplo, la cobertura general cayó del $80 \%$ en 1990 al 27\% en 1998; en Togo, pasó del 100\% al $54 \%$. El resultado fueron 3 millones de muertes al año por enfermedades para las cuales existían alternativas de cura (Hardon, 2001).

En cuarto lugar, porque los cambios que se profundizaron como resultado de la globalización cambiaron los ecosistemas, y con ello la substitución de unas enfermedades por otras. El despoblamiento del campo, derivado de la mecanización agrícola en algunos casos, o de la erosión en otros, agudizó la migración rural-urbana y el hacinamiento en ciudades sin las condiciones sanitarias y de distribución de agua necesarias, proceso que se profundizó notablemente en el Tercer Mundo durante los años ochenta y noventa. Junto a ello, el paisaje rural cambió, en algunos lugares con amplias zonas de monocultivo, en otros con la desecación de terrenos húmedos, en otros con diques y canales de riego, en otros con la substitución de la agricultura por la ganadería, en otros por la deforestación de los bosques o por su expansión allí donde substituyó a cultivos agrícolas o áreas de pastoreo, y así en general. También el calentamiento global puede facilitar la expansión de determinadas enfermedades tropicales a los países templados.

En quinto lugar, el crecimiento de las migraciones internacionales, sea por causas económicas o de guerras, ayudan al desplazamiento de las enfermedades ${ }^{6}$. El comercio de mercancías, sumamente incrementado durante las últimas décadas, da lugar al transporte asociado e involuntario de microbios. El transporte aéreo lleva inadvertidamente virus y bacterias junto con sus pasajeros y objetos ${ }^{7}$.

\footnotetext{
6 "El resultado neto es que mucha tuberculosis que se ve en los países desarrollados hoy en día es en inmigrantes. En torno al $36 \%$ de los casos de tuberculosis en paises desarollados es de los nacidos en el extranjero, y el porcentaje está incrementándose. Como es esperado, los inmigrantes de los países donde la incidencia de la tuberculosis es alta tienen un elevado riesgo de desarrollo de la tuberculosis, especialmente si emigraron después de los cinco años, cuando la infección latente generalmente está bien establecida" (Coberly, 2000).

7 "La reciente invasión en los Estados Unidos por los long horned beetles, que llegaron de la China en cajas de madera, se espera que cueste a la nación en torno a 669 mil millones de dólares sólo en árboles destruídos por los insectos en áreas urbanas en las próximas décadas" (Weis, 2002).
} 
RIS

REVISTA INTERNACIONAL DE SOCIOLOCIA

№ 34, Enero - Abril, 2003

GULLLERMO FOLADORI

\section{LA ORIENTACIÓN MERCANTIL DE LA CIENCIAY LA TECNOLOGÍA (C Y T) EN MATERIA DE MEDICINAS}

Es claro que una política de $\mathrm{C}$ y $\mathrm{T}$ en salud debería analizar todas esas tendencias y cambios, para poder orientar la investigación en función de las necesidades sociales. Pero ese no es el caso, ni podría serlo con la actual estructura de investigación y producción de medicamentos.

La investigación biomédica está altamente dividida en el mundo. No toda la investigación se desarrolla en las grandes empresas farmacéuticas. Mucha investigación básica se realiza en las universidades, hospitales y centros públicos de investigación. Y a partir de los años setenta del siglo XX los avances tecnológicos han permitido la introducción de pequeñas empresas en el mercado. Por un lado, con el descubrimiento del mecanismo mediante el cual parte de un gen puede ser insertado en otro, cambiando sus características (rDNA), y permitiendo la producción de vacunas y medicinas con esta técnica. Por otro lado, se han desarrollado técnicas para fusionar y multiplicar células (hybridomas). Surgieron así nuevas empresas de biotecnología de menor tamaño, al reducirse la escala necesaria para el descubrimiento de una droga (Simpson, 2002; Kettler, 2002c).

Pero el iniciar una nueva droga no es igual a su desarrollo (pruebas, etc.) y posterior comercialización. Para esto último las pequeñas empresas de biotecnología no tienen otra alternativa que ser subcontratadas o asociarse con las grandes transnacionales (Sussex \& Marchant, 2002; Kettler, 2002c). Lo mismo sucede con la investigación pública allí donde la estructura de la salud pública o los derechos de propiedad intelectual impiden que la medicina producida por estas instituciones llegue al consumidor.

De manera que no importa si los primeros pasos en el desarrollo de una nueva droga fueron dados en instituciones públicas o en pequeñas empresas privadas, el resultado es que su lanzamiento al mercado como medicina patentada es realizado mayoritariamente por las grandes industrias farmacéuticas ${ }^{8}$. De un total de 196 nuevas drogas (Nuevas Entidades Químicas, NEQ) aprovadas por la Food \& Drug Administration de los Estados Unidos entre 1981 y 1990, 92\% fueron desarrolladas por la industria farmacéutica (Montaner et al., 2001). Aunque esto no significa que las inversiones sean completamente privadas, $\mathrm{y}$ tampoco que estas empresas privadas no utilizen información previa desarrollada en instituciones públicas. Muchos antiretrovirales para combatir el SIDA fueron inventados en

\footnotetext{
8 "Mientras que la investigación en ciencia básica tiene lugar en las universidades o en laboratorios gubernamentales, el desarollo de la droga es realizado casi exclusivamente por la industria farmacéutica (pharma). La selección de promisorias candidatas a drogas por la pharma está basada en los beneficios potenciales para la compañía y sus accionistas, no en preocupaciones de salud pública mundial. Este sistema, obviamente, no satisface las necesidades de los paises pobres" (Zumla, 2002: 393).
} 
los Estados Unidos a partir de financiamientos públicos. Es conocido que las empresas farmacéuticas utilizan fondos públicos directos en forma de subsidios o de pruebas realizadas en instituciones públicas, o indirectos como reducción de impuestos, para realizar ganancias privadas a expensas de los consumidores (Love, 2000).

Como es norma en cualquier empresa, el objetivo principal y que garantiza su sobrevivencia es la ganancia. La industria farmacéutica no escapa a esa ley de la competencia capitalista. Si la producción de medicamentos no ofrece una tasa de retorno del capital invertido igual o mayor a la que surge de la aplicación en otras ramas económicas los accionistas venderán y la producción caerá; cuanto mayor sea la tasa de retorno del capital más eficiente es la empresa y más accionistas atrae. El gráfico 1 muestra cómo el grueso del mercado farmacéutico está concentrado en los países desarrollados. Véase que entre Norte América, Japón y Europa, que suman el $23 \%$ de la población mundial, cubren el $80 \%$ del mercado de medicamentos, dejando a la mayoría de los países de menores ingresos prácticamente sin cobertura de medicinas.

Esta contradicción entre necesidades e investigación científica se conoce como la "brecha 10/90", que significa que sólo el $10 \%$ de los fondos son dirigidos a investigar en enfermedades responsables del $90 \%$ de la carga de enfermedad mundial 9 .

Gráfico 1.

Distribución del mercado farmacéutico comparado con la distribución de la población mundial.

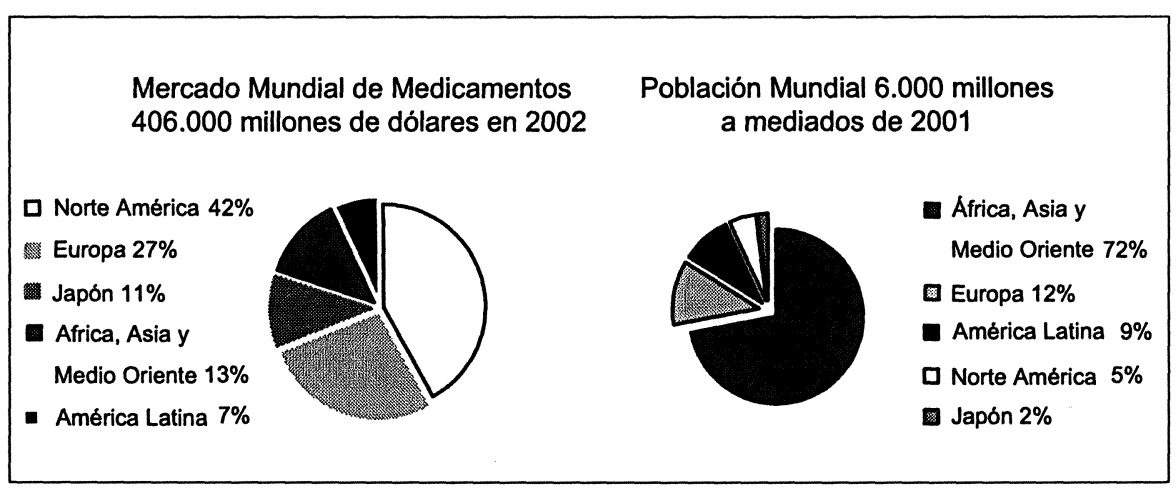

Fuente: MSF/DND, 2001.

\footnotetext{
${ }^{9}$ La medida de carga de la enfermedad o DALY fue introducida por la Organización Mundial de la Salud a mediados de los años noventa del siglo XX para medir el peso de las enfermedades
} 
Cuando el $90 \%$ de la carga de enfermedad está en los países pobres, y los enfermos no tienen el poder adquisitivo necesario para comprar medicinas, no existe mercado. Las necesidades, por sí solas, no crean mercado, se necesita poder de compra para crear mercado. De manera que surge una contradicción entre los - por ejemplo- 18 millones de personas que murieron de enfermedades comunicables en 2001 - la mayoría de las cuales no tenían ingresos suficientes para pagar las medicinas-y las empresas farmacéuticas que producen medicamentos para los ricos, que sí tienen poder adquisitivo. El Director General de la Federación Internacional de la Asociación de Industrias Farmacéuticas (IFPMA) dijo en la revista The Economist del 28 de Abril de 2001 que "aun a los precios más bajos mucho de los pobres del mundo no tienen acceso a los tratamientos para la malaria, tuberculosis y otras enfermedades". Con ello desnuda la realidad: bajo un sistema de producción mercantil no se puede tener acceso a medicamentos sin dinero; $y$ también deja ver que, él mismo, no se imagina ninguna manera diferente (como podría ser el sistema público subsidiado) para que los enfermos tengan acceso a los medicamentos.

Un claro indicador de la existencia de enfermedades no atendidas por la industria farmacéutica son los resultados de la investigación y desarrollo de drogas. Según un informe de Médicos sin Fronteras, entre 1972 y 1997, cerca de 1.450 nuevas drogas (NEQ) fueron comercializadas. Pero, de ellas, sólo trece eran para tratar enfermedades tropicales transmisibles y consideradas como esenciales según el modelo de la Organización Mundial de la Salud. Dos de esas trece eran versiones actualizadas de otras ya existentes, dos eran resultado de investigación militar, cinco fueron resultado de investigaciones veterinarias, una derivaba de la farmoscopía China. De manera que sólo tres pueden ser consideradas como genuinos productos de investigación y desarrollo de las compañías farmacéuticas occidentales (Trouiller et al., 1999).

Pero, ¿se puede acusar a la industria farmacéutica de no investigar y desarrollar medicamentos que no dan ganancia, o que dan menores ganancias que otros? También en las últimas décadas se han realizado investigaciones para determinar los márgenes de lucro de la industria farmacéutica. Aunque esto parezca simple, es sumamente complicado. Las contabilidades pueden fácilmente esconder las ganancias en los salarios de los ejecutivos, o en regalías, o pueden confundir las donaciones y subsidios dentro de los costos, o pueden no considerar la exoneración de impuestos, o las ganancias derivadas del licenciamiento de drogas de otras industrias, o las contribuciones hechas por instituciones públicas, pueden

\footnotetext{
en términos de los años de vida perdidos. El DALY combina información del impacto de la muerte prematura y de indisposición, así como otros resultados no mortales. Cada DALY puede entenderse como un año de vida sana perdida, y la carga de la enfermedad como la brecha entre el nivel actual de salud y la situación ideal en la cual todos viven hasta la edad adulta sin enfermedades e indisposiciones.
} 
no considerar adecuadamente el ciclo de rotación del capital, etc. Grabowski \& Vernon (1994) llegan a la conclusión de que sólo las principales drogas en circulación permiten recuperar los costos y ganancias de muchas otras que, por sí mismas, darían pérdidas. Esto es importante, porque muestra que para una empresa farmacéutica - como para cualquier empresa de otro ramo de producción- la relación costo-beneficio se debe hacer en función de todas las mercancías producidas, y no una por una. Además, las nuevas drogas (NEQ) tardan de 10 a 12 años en recuperar sus inversiones y ganancias correspondientes. La propia industria farmacéutica argumenta que los costos de investigación y desarrollo en el área son muy elevados; y que las barreras reglamentarias extienden el tiempo entre el desarrollo de la droga y su comercialización de 8 a 10 años - debe considerarse el tiempo de implementación y resultado de las pruebas, el proceso administrativo de certificación, etc ${ }^{10}$. También argumentan - contradictoriamente, porque se ven beneficiadas cuando participan de la ventaja - que los derechos de propiedad (usualmente de 20 años) dificultan el ingreso al mercado de otras medicinas, lo que incrementa los costos de "espera".

Contra las dificultades económicas anteriores, otros estudios muestran que la industria farmacéutica es una de las más rentables. La revista Fortune consideraba, para 2001, a la industria farmacéutica la más rentable, con $16,2 \%$ de retorno, seguida por el sector financiero con $11,6 \%$ (Fortune, 2002). También se ha ido concentrando en pocas multinacionales en los últimos años, lo que sería un indicador de su fortaleza financiera. Kettler (2002a) compila investigaciones sobre el monto necesario para lanzar una nueva droga (NEQ) al mercado, y su tendencia al incremento en los últimos años (tabla 1). Y, agrega que, según la empresa Zeneca-Lehman Brothers, los costos totales de investigación y desarrollo para una nueva droga en la segunda mitad de los noventa alcanzaban los 635 millones de dólares, superando los datos del último estudio anotado en el cuadro.

Pero esta información puede interpretarse como un signo de vitalidad o de debilidad de la industria farmacéutica. Es cierto que el mayor volumen de capital invertido por cada nueva droga significa una concentración del capital; pero, también es cierto que los costos de producción suben crecientemente y obligan a la venta de cada vez más medicamentos para recuperar el capital. Por otra parte, quinientos millones de dólares o más, para desarrollar una nueva droga, puede parecer exagerado, a juzgar por comparaciones con lo que sucede en instituciones públicas. En 1988 el Instituto Nacional del Cáncer de los Estados Unidos estima haber gastado entre 2,3 y 6 millones para investigación y desarrollo de una nueva droga, y a pesar de que estos datos pueden no contener el valor definitivo, están

\footnotetext{
${ }^{10}$ Una industria farmacéutica puede perder en promedio más de mil dólares por cada día que se atrasa su aprobación por la Food \& Drug Administration de los Estados Unidos (Abraham, 2002).
} 
RIS

REVISTA INTERNACIONAL DE SOCIOLOCIA

№ 34, Enero - Abril, 2003

GUILLERMO FOLADORI

Tabla 1.

Costo estimado de lanzar una "nueva entidad química" al mercado (millones \$1997).

\begin{tabular}{lcc}
\hline Estudio & Años $^{*}$ & Total de costos \\
\hline Hansen, 1979 & $1963-75$ & 138 \\
Wiggins, 1987 & $1963-75$ & 156 \\
DiMasi et al., 1991 & $1970-82$ & 312 \\
OTA, 1993 & $1970-82$ & 431 \\
Myers and Howe, 1997 & $1970-82$ & 459 \\
\hline
\end{tabular}

Fuente: tomado de Kettler (2002a).

* "Años" se refiere a los años en que el producto en estudio entra en la fase de prueba.

muy lejos de los 500 millones que supuestamente requiere la industria farmacéutica (Geffen, 2001) ${ }^{11}$. La asociación entre instituciones públicas y privadas Global Alliance for TB Drug Development calcula que se necesitan entre 115 y 240 millones de dólares para desarrollar una nueva droga, otra vez muy lejos de las estimaciones de la industria farmacéutica (Henry \& Lexchin, 2002).

Otra crítica a la industria farmacéutica dice que el gasto en publicidad es mucho mayor que en investigación y desarrollo de drogas (Angell, 2000). Que incluso la información al público y a los profesionales de la salud sobre los efectos benéficos de la droga es una parte menor del gasto en publicidad ${ }^{12}$. Estiman, por ejemplo, que en el Reino Unido aquellas empresas que participan del Pharmaceutical Price Regulation Scheme gastan 5 libras para promoción, por cada libra gastada en información (Collier \& Theanacho, 2002). Pero, ¿no son los gastos de publicidad parte de los costos de producción en cualquier empresa capitalista? Lo mismo podría reclamarse de los costos de publicidad en el precio de venta de los autos o de los productos de limpieza.

En contra de la industria farmacéutica también se argumenta la duplicación de esfuerzos en investigación y desarrollo. El ejemplo que más impacta es el de las me

\footnotetext{
11 "Es interesante que en 1988, El Instituto del Cáncer de los Estados Unidos estimó que gastaba un promedio de entre 2,3 y 6 mil millones de dólares americanos en investigación y desarrollo de una nueva droga hasta el final de la fase III de las pruebas. Esto no incluye los ajustes por inflación, los costos de oportunidad del capital o los ajustes por riesgos de drogas que no son bien sucedidas. Pero aún tomando esto en cuenta, la estimación por las compañias farmacéuticas de más de a 500 millones de dólares para I+D de una nueva droga implica o una ineficiencia masiva o una exageración" (Geffen, 2001:15).

${ }^{12}$ Las compañías farmacéuticas argumentan que gran parte del gasto en marketing es en realidad en educación, ya que tienen que informar a los médicos y al personal de salud sobre las características del medicamento.
} 
too drugs, o medicamentos que son copia de prototipos lanzados al mercado por empresas competidoras. Estos medicamentos tienen principios activos semejantes, y buscan ganar una parcela de los clientes que consumen el prototipo. Esto significa un esfuerzo redundante en materia de investigación ${ }^{13}$. Significa un derroche de tiempo y materiales que podrían ser utilizados en la investigación de nuevos prototipos, o en el abaratamiento de los medicamentos existentes (Garanttini, 1997). Nuevamente se trata de un argumento de gran peso ético, pero de poca utilidad práctica. En cualquier rama de la industria existen competidores que tienen que desarrollar en forma independiente, duplicando esfuerzos, lo que otras industrias ya han hecho. La duplicación de esfuerzos, o el "desperdicio" - si se quiere-de materiales y energía humana en investigar lo que ya está investigado, o en introducir pequeñas variaciones a mercancías ya existentes, o en cambiar la forma y apariencia de un mismo contenido, es la esencia de la producción capitalista. De otra forma no habría competencia ni libertad de mercado.

También podría argumentarse, en contra de la industria farmacéutica, la política de "archivo" de conocimiento científico que no tenga resultados económicos claros. Como sucedió con la tuberculosis, donde se han hecho importantes avances en el conocimiento desde 1970 pero sin culminación en medicamentos por falta de perspectivas de ganancia (Farmer, 1999). O, también, las trabas legales y burocráticas que las empresas establecen con competidores para "ganar tiempo", o impedir que información perjudicial sea hecha pública por sus propios investigadores o por investigadores asociados de centros independientes de investigación (Collier \& Iheanacho, 2002) ${ }^{14}$. O los mecanismos para "eternizar" las patentes (evergreening) mediante artificios como registrar otros usos para drogas cuyas patentes están venciendo, reclamos legales por acciones contra las patentes vigentes que pueden extender el periodo de vigencia hasta en un mes, etc. (Henry \& Lexchin, 2002; Barret, 2001; Angell, 2000). O, también, procedimientos para ampliar el uso de medicamentos aprobados para determinados fines, hacia otros fines sin la necesaria aprobación y utilizando lagunas de la ley (Armstrong \& Forelle, 2002).

\footnotetext{
${ }^{13} \mathrm{La}$ información de investigación sobre drogas es un secreto de la industria farmacéutica. Incluso una vez que se presenta la droga para su certificación frente al gobierno, la información ofrecida es sólo una parte de la existente, de manera que los investigadores de otras empresas no tienen acceso a la información completa (Collier \& Iheanacho, 2002).

14 “ Ocasionalmente, buscando asegurar una posición beneficiosa, las compañias han encaminado acciones legales para parar de hecho la publicación de material negativo por parte de investigadores independientes... Más aún, investigadores que comunican resultados negativos han sufrido intimidaciones, esfuerzos por desacreditarlos profesionalmente, $y$ tretas de acciones legales para recuperar el valor de las ventas perdidas. A menudo, las posibilidades para la intervención de las compañías está escrito en los contratos del investigador. Por ejemplo, en una muestra de centros de investigación de los Estados Unidos, cerca del $30 \%$ de los contratos con investigadores permitían a las compañías que los promocionaban borrar información de los informes y atrasar su publicación" (Collier \& Iheanacho, 2002).
} 
R I S

REVISTA INTERNACIONAL DE SOCIOLOGIA

№ 34, Enero - Abril, 2003

GULLLERO FOLADORI

Para tratar de resolver teóricamente esta chocante contradicción entre principios éticos y lógica económica, algunos autores argumentan que se trata de una falla del mercado. Si la gran mayoría de los enfermos no tienen dinero suficiente para comprar el medicamento, o la industria farmacéutica no investiga en medicinas para curar enfermedades de pobres es porque hay una falla en el mercado (Brundtland, 2001) ${ }^{15}$. Pero, este argumento también puede ser fácilmente criticado. Si el problema es de una falla del mercado, no habría rama de la producción donde no fallara, ya que hay en el mundo 1.200 millones de indigentes que prácticamente no pueden comprar nada. En realidad no es la falla del mercado, sino su buen funcionamiento lo que origina esas desigualdades. En el caso de las medicinas esa contradicción adquiere un marco ético porque muestra que la producción para el mercado no puede dedicar sus enormes avances en materia de ciencia y tecnología a solucionar los principales problemas de salud del mundo ${ }^{16}$."

Más allá de la discusión sobre las ganancias de la industria farmacéutica o su orientación en materia de producción de medicamentos, la industria está pasando por una fase de concentración y centralización del capital, y también de relocalización espacial. Durante los años noventa se fue formando un corredor en el noreste de los Estados Unidos, entre Boston al norte y el Distrito de Columbia al sur, en el cual se ubican 15 centrales de las 20 principales industrias farmacéuticas y de biotecnología del mundo. Mientras todas las industrias han perdido, en los dos primeros años del siglo XXI 220.000 empleos en el área de ese corredor

\footnotetext{
${ }^{15}$ Algunos, incluso, se valen del concepto económico de "externalidad". Las externalidades son resultados no buscados, positivos o negativos, que la producción puede generar sobre terceros. Es un concepto ampliamente utilizado en cuestiones ambientales. Cuando una fábrica contamina el aire de un barrio está generando una externalidad negativa para los habitantes. Las externalidades son consideradas como fallas del mercado que deben ser corregidas a través de políticas. Los bonos de emisión de contaminantes negociados en el mercado o los impuestos sobre el tipo y volumen de emisión son mecanismos de política económica utilizados por muchos gobiernos para corregir esas fallas del mercado, e internalizar las externalidades. En el caso de la salud la externalidad negativa seria el no investigar en medicamentos de enfermedades cuyos portadores no tienen poder de compra. A diferencia del ejemplo de la fábrica que contamina, es una externalidad por la negativa, por no hacer, en lugar de por producir. Utilizar, en estos casos, el concepto de externalidad cumple con la función ideológica de defender el derecho de la industria farmacéutica de no producir, y de reclamar la necesidad de una solución ética.

${ }^{16}$ Esto no significa que no existan fallas en el mercado de medicinas. También existen. Por ejemplo, un informe del Federal Trade Commission's Bureau of Competition (2001) contiene detallados datos de tres empresas que incurrieron, a finales de los noventa, en acciones monopólicas ilegales o en coimas para evitar la competencia. Laboratorios Abbott pagó 4,5 millones de dólares al mes durante el periodo de litigación de la patente a Geneva Pharmaceuticals para que no produjera el genérico competitivo con su droga Hytrin. Hoechst Marion Roussel (Aventis) pagó a Andrx Corporation más de 80 millones durante el periodo de litigación de la patente para evitar que entraran con droga genérica competitiva a la Cardizem $C D$. Schering-Plough Corporation pagó 30 millones a Upsher-Smith Laboratories y a ESI Lederle, Inc. para que no entrara con versiones genéricas del pro-
} 
geográfico, las actividades de salud han incrementado los empleos en 50.000. Varios elementos justifican esta relocalización en un área donde desde hace un siglo existe una fuerte base de hospitales e industrias farmacéuticas. La cercanía de Washington DC es de importancia para el lobby político (Galeria, 2001) ${ }^{17}$. Se estima que un $60 \%$ de los aportes a las campañas presidenciales provienen de ese sector, y la industria tiene un lobbista por cada dos congresistas. En las afueras del Distrito de Columbia, en Maryland, está el National Institute of Health, que utiliza fondos públicos para investigación básica que luego es utilizada por las empresas privadas. Dieciseis de los principales cincuenta hospitales e institutos médicos están localizados en el área. Importantes centros universitarios como la Harvard Medicine School, o la John Hopkins, o la University of Pensilvania, el Massachussets General Hospital, la Tufts University Center for Drug Development, etc., todas ellas aportan el contingente de talentos necesarios para la industria. Pharmacia, por ejemplo, se trasladó de Londres a Nueva Jersey a finales de los noventa, y luego fue comprada por Pfizer. Novartis, con base en Suiza, está instalando un centro de investigaciones en Cambridge (Massachussets); Altana, de Alemania, abrió recientemente una oficina en Nueva Jersey (Leonhardt, 2002). El mercado de medicinas más importante también está en los Estados Unidos, con los mayores precios de los medicamentos y un sistema de salud totalmente privatizado que constituye el ideal para la industria farmacéutica y el suplicio para los enfermos.

\section{RECIENTES CAMBIOS EN LA CRISIS DEL MERCADO DE SALUD}

Los países desarrollados comenzaron a preocuparse explícitamente por las enfermedades de los pobres a medida que estas enfermedades se expandían al primer mundo, o que los pobres de los países desarrollados se organizaban para reclamar atención sanitaria. Una combinación de ambas causas es el caso del SIDA, donde tras su ingreso en los Estados Unidos y Europa, y de las demandas de sus enfermos, la industria farmacéutica logró importantes avances en poco tiempo, con la producción de cócteles que mejoran y alargan la vida ${ }^{18}$. Pero allí donde

\footnotetext{
ducto $k$-Dur y por la licencia de productos de la ESI. Mylan Laboratories, Inc., incrementó el precio como resultado de un acuerdo con los suministradores de los ingredientes activos claves. En 1998 aumentaron el precio al mayoreo del clorazepate de 11.36 hasta 377 dólares el frasco de 500 tabletas, y también de lorazepam, que pasó de 7,3 a 190 dólares el frasco de 500 tabletas. Los consumidores americanos tuvieron que pagar 120 millones más (Federal Trade Commission, 2001).

17 "Se estima que las compañías farmacéuticas se gastan todos los aos 75 millones de dólares en presionar al gobiemo de los Estados Unidos, lo que explica el apoyo qe Washington les concede" (Galeria, 2001).

${ }^{18} \mathrm{Las}$ primeras catorce drogas antirretrovirales para el tratamiento del SIDA llevaron un promedio de 4 a 5 años para su desarrollo, mientras que el promedio para una nueva droga es de aproximadamente 12 años.
} 


\section{RIS}

las enfermedades se restringen mayoritariamente a los países del Tercer Mundo los avances no son iguales, por lo que aún no hay medicamentos adecuados para muchas de las enfermedades infecciosas tropicales, como la tuberculosis, el dengue o la malaria. No obstante, las enfermedades infecciosas y de parásitos son responsables de más del $40 \%$ de la carga total que las enfermedades causan a la sociedad (WHO, 2002), además de tratarse de enfermedades teóricamente posibles de ser tratadas. Pero esta situación está cambiando por diversas razones.

a) Por la creciente movilización de organizaciones de enfermos y ONG que defienden sus intereses. Esta movilización ha hecho explícita la contradicción entre quienes representan los intereses de los millones de enfermos por enfermedades infecciosas que no tienen cura, o cuyas medicinas tienen un precio que no está a su alcance, y los representantes del capital farmacéutico transnacional y sus defensores como la Organización Internacional del Comercio o los gobiernos de los Estados Unidos y Europeos, que anteponen las ganancias a los intereses humanitarios (Love, 2001; Angell, 2000). En los últimos años las movilizaciones han hecho importantes avances, no definitivos, en su favor, y en detrimento de los intereses del capital farmacéutico internacional. Han presionado, por ejemplo, para que países como Brasil comenzaran a producir medicinas genéricas para el tratamiento del SIDA, desatendiendo a la reglamentación de propiedad intelectual en patentes (TRIPS) defendida por la Organización Internacional del Comercio ${ }^{19}$. Han obligado a la industria farmacéutica a bajar los precios de los medicamentos para el SIDA que se venden en algunos países del Tercer Mundo ${ }^{20}$. Han obligado a que la Organización Internacional del Comercio emitiese, en 2001, la declaración de Doha, que establece una flexibilización de su reglamentación de patentes, permitiendo que los países con epidemias produzcan genéricos competitivos con los medicamentos de marca, reconociendo formalmente lo que ya se había conseguido por la vía práctica ${ }^{21}$. El Parlamento Europeo fue aún más allá, y aprobó,

\footnotetext{
${ }^{19}$ En 2001, al no llegar a un acuerdo con la transnacional Roche, productora de la droga nelfinavir, Brasil comenzó a producir genéricos, incumpliendo con los acuerdos de propiedad intelectual (TRIP) de la Organización Internacional del Comercio (Donnelly, 2001).

${ }^{20}$ Como consecuencia de la presión que la producción de genéricos provocó, Brasil consiguió negociar con la Merck una disminución del $65 \%$ en el precio del Indinavir y del $59 \%$ en el precio del Efavirenz (parte del cocktail para combatir el SIDA) (Ministério da Saúde, 2002). "Las gigantes farmacéuticas -incluyendo las que tienen base en los Estados Unidos como Merck, Pfizer y Bristoladmiten que pueden vender drogas contra el SIDA en el mundo en desarrollo con descuentos de hasta $90 \%$ y aún obtener ganancia" (Galeria, 2001).

${ }^{21}$ Algunos trechos de la declaración de Doha dicen: "Reconocemos que bajo las reglas de la OMC para la protección de la vida o la salud humana, de animales o de plantas... Reafirmamos la importancia que damos a la implementación e interpretación del acuerdo sobre derechos de Propiedad Intelectual y aspectos relacionados con el comercio de manera que se apoye a la salud pública, promoviendo tanto el acceso a las medicinas existentes como la investigación y el desarrollo de nuevas medicinas. Durante una emergencia nacional como Sida, tuberculosis, malaria
} 
en 2002, que medicamentos genéricos pueden ser vendidos desde terceros países, superando así el problema de los países pobres que no pueden usufructuar el derecho de producir genéricos por falta de desarrollo de la industria farmacéutica local (Loff, 2002a).

b) Por la alarma que crean las movilizaciones de pobres y enfermos en defensa de sus derechos. En la última década han surgido varias organizaciones que pretenden negociar entre el capital farmacéutico transnacional y las instituciones públicas y organismos internacionales, con el propósito humanitario de dar una solución al problema mediante donaciones, y el político de contener las movilizaciones lo más posible dentro de los derechos de propiedad ${ }^{22}$. Es el caso, por ejemplo, del Global Forum for Health Research, una fundación internacional independiente establecida en 1998 con el objetivo de corregir la "brecha 10/90" en investigación en salud. El propio objetivo es el reconocimiento internacional más claro de que el mercado no es el mejor asignador de recursos en ciencia y tecnología para el área más vital de la humanidad. Pero estas negociaciones son difíciles, y en su informe anual 2001-2002 el Global Forum for Health Research reconoce que el problema persiste casi igual que hace 11 años cuando fue encomendada la fundación de la institución (Ramsay, 2001). Otros ejemplos son la Global Alliance for Vaccines and Immunisation, que incluye la Fundación Gates, o la Medicines for Malaria Venture (Kettler, 2002b). Las mayores facilidades administrativas otorgadas, en 2002, por el Parlamento Europeo y el gobierno de los Estados Unidos (Rogers, 2002) para que los medicamentos genéricos entren en el mercado una vez vencidas las patentes, deben leerse como un resultado de esas luchas sociales, y la búsqueda de garantizar los derechos de propiedad con modificaciones que hagan más eficiente la producción privada de medicamentos.

c) Por la propia posibilidad de la expansión de las epidemias a los paises desarrollados. Las enfermedades infecciosas se han vuelto un problema global debido a las migraciones, el turismo y el comercio internacional, ya que bastan

\footnotetext{
y otras epidemias, es permisible que un país emita una licencia obligatoria para que un 'tercer partido' productor, pueda abastecer de una medicina para el uso doméstico, aun estando la droga bajo patente". Pero, no obstante este avance aparente, en la práctica no han habido resultados en la reglamentación de esta declaración, y los Estados Unidos y otros países desarrollados insisten en la posición de las transnacionales farmacéuticas de limitar los países y las enfermedades que se incluyan en la declaración (Loff, 2002b).

${ }^{22}$ Las reclamaciones de los enfermos son vistas como brotes de inestabilidad política que pueden llevar a revueltas sociales. Un reciente discurso de la directora de la Organización Mundial de la Salud es elocuente respecto a eso, al decir: "Un mundo en donde la división entre los ricos y los pobres continúe incrementándose, un mundo en donde sólo unos pocos privilegiados tienen acceso a los frutos de la revolución tecnológica, es un mundo que será cada vez más inseguro. En el pasado, condiciones deseperadas en otro continente podían ser cínicamente borradas de nuestra memoria. El proceso de globalización ya ha hecho tal opción imposible" (Brundtland, 2001).
} 
RIS

REVISTA INTERNACIONAL DE SOCIOLOGIA

No 34, Enero - Abril, 2003

GUILLERMO FOLADORI

pocas personas infectadas para crear una epidemia en otros países. Hace menos de un siglo, cuando sucedía una epidemia todos los pasajeros y tripulación del barco eran retenidos en cuarentena, en islas o establecimientos aislados de las ciudades. Esto ya no es posible debido al movimiento más individual, diverso y descentralizado del turismo internacional. Dieciseis millones de personas mueren anualmente por enfermedades infecciosas, y a pesar de que el $90 \%$ de esos casos ocurre en los países del Tercer Mundo, la posibilidad de epidemias en los países desarrollados no se puede descartar. También el calentamiento global puede favorecer la expansión de las enfermedades tropicales a los países de clima templado, con consecuencias imprevistas una vez que se expandan en nuevos hábitats.

d) Por la crisis de los sistemas públicos de salud en los paises desarrollados. A partir de la década de los noventa, los sistemas de salud de los países desarrollados entraron en crisis, como consecuencia del envejecimiento de su población y la reducción del tiempo de trabajo, sumado al hecho de que los costos de mantenimiento del sistema están prioritariamente basados en los salarios $u$ horas de trabajo, en lugar de las ganancias (Evans, 1994). El resultado es que los presupuestos estatales no son capaces de mantener, con ese sistema de cobranza, una cobertura decente para toda la población ${ }^{23}$. En el caso de que suceda una epidemia de enfermedades "tropicales", la posibilidad de reacción de estas instituciones es muy discutible, tanto por razones financieras como por el desconocimiento y falta de experiencia en la atención por parte del personal de salud. Pero se trata de posibilidades reales, si pensamos que muchas de esas enfermedades no son exclusivas de países tropicales, como la malaria, que a mediados del siglo XIX era una importante causa de muerte en muchos estados de los Estados Unidos, $\mathrm{y}$ aunque ahora los ecosistemas no son los mismos otras pueden tomar su lugar, como la tuberculosis, etc. (Farmer, 1996).

e) Por la eventualidad de que virus o bacterias puedan ser usados como armas terroristas. La guerra encabezada por los Estados Unidos frente a Irak tuvo como justificativa explícita la posibilidad de atentados bio-terroristas. El tema es considerado en los Estados Unidos como un problema de seguridad nacional, como lo indica la existencia de un grupo específico encargado de ello en la Central de Inteligencia Americana (CIA, 2000). Esta posibilidad obliga al despliegue de información, infraestructura y materiales para el combate de las posibles enfermedades infecciosas. Como la del actual gobierno de los Estados Unidos, que planea vacunar a toda su población contra la viruela, una enfermedad supuestamente erradicada.

\footnotetext{
${ }^{23}$ La European Federation of Pharmaceutical Industries and Associations (EFPIA) estima que el gasto en drogas por parte de los sistemas de seguros de salud en Europa en 2001 duplicó los gastos que se venían dando en la década anterior (Rogers, 2002). Los gastos en medicamentos son los que más rápidamente crecen de todos los gastos de salud en los Estados Unidos (Angell, 2000).
} 
f) Por el incremento de costos derivados del deterioro de la fuerza de trabajo en las zonas de mayores epidemias. En una nota de la revista The Economist (05/10/2002) se plantea la preocupación de los empresarios de África del Sur a causa de la epidemia de SIDA. Varias compañias mineras comenzaron, en el año 2002, a pagar los medicamentos para sus obreros infectados. A pesar de que puede significar un aumento de más del $5 \%$ en los costos, resulta más barato que capacitar nuevos trabajadores con el riesgo de no saber durante cuánto tiempo estarán $\operatorname{sanos}^{24}$. Y no son sólo las empresas en funcionamiento las que están preocupadas con las epidemias. Las posibilidades de nuevas inversiones de capital aumentan significativamente su riesgo en los lugares de epidemia. La India, un promisorio mercado para la industria de la computación, puede ver su población diezmada como consecuencia del avance del SIDA. Para el año 2010 se estima que tendrá entre 20 y 25 millones de infectados. La empresa Microsoft, que emplea un importante número de personal especializado hindú y que además está interesada en entrar masivamente en el mercado, acaba de donar a través de su fundación Gates, 100 millones de dólares para combatir el SIDA, al mismo tiempo que invertirá 400 millones de dólares en los próximos tres años, siendo la mayor inversión de la empresa fuera de los Estados Unidos. Los intereses humanitarios pueden a veces subsumirse a los del mercado (Lancet, 2002). En Holanda, la organización sin fines de lucro Lange's International Antiviral Therapy Evaluation Center propuso un acuerdo entre el sector privado y las empresas farmacéuticas (Gellman, 2000b) ${ }^{25}$. Esta situación genera una fuerte contradicción entre el capital de la industria farmacéutica y el que se destina a otras esferas de la actividad económica, que presiona a sus gobiernos para que asuman la responsabilidad de la salud pública y, con ello, están a favor del abaratamiento de los medicamentos y en contra del capital farmacéutico.

El resultado general de estos cambios es aún incierto. Dos polos parecen competir por convertirse en atractores del posible desarrollo: el control de los fondos públicos nacionales e internacionales por las grandes empresas farmacéuticas a

\footnotetext{
24 "Las firmas están comenzando a ver una pérdida de productividad, baja moral, absentismo, y la muerte de trabajadores entre los 20 y 40 años de edad. En la medida en que trabajores adiestrados y con experiencia mueren, sus firmas se enfrentan a aumento de costos de entrenamiento y pérdida de valiosa know-how, así como la necesidad de negociar con colegas agobiados por la desgracia. Aun para trabajadores no cualificados, hay costos extra en su contratación y pagos por absentismo por enfermedad. Anglo-Gold, por ejemplo, estima que el virus agrega de 6 a 170-180 dólares a los costos de producción de una onza de oro... Proveer medicinas, educar a los trabajadores y tratar las enfermedades infecciosas puede ser, en algunos momentos, la opción más barata para la empresa" (Economist, 2002).

${ }^{25}$ "Tras seleccionar protocolos simples de tratamiento, el grupo holandés llegó a muchos empleadores en Africa. Lange razonó que las corporaciones enfrentadas 'a la pérdida de la mitad de su fuerza de trabajo cualificada' pueden estar más motivadas, financiera y organizativamente para subsidiar tratamientos del Sida, que el gobierno local" (Gellman, 2000b).
} 
RIS

REVISTA INTERNACIONAL DE SOCIOLOCIA

№ 34, Enero - Abril, 2003

GULLERMO FOLADORI

través de asociaciones público-privado (private-public partnerships); o el control del sistema de salud por el sector público. Por un lado, parece que la industria farmacéutica está perdiendo terreno, y las organizaciones que defienden a los enfermos han ganado importantes victorias, a pesar de que cada paso lleva años y, por tanto, millones de muertos para alcanzarlo. Pero ese triunfo no es definitivo. Hay, por otro lado, una gran preocupación de gobiernos e instituciones internacionales por "hacer entrar en razón" a la industria farmacéutica, llevándola a participar de acuerdos multilaterales que pueden implicar disminución o aumento de sus ganancias, pero con el propósito no explícito de garantizar la defensa de la propiedad privada de los derechos intelectuales y del sistema de mercado en general. Una vez más, el problema de la salud se inclina entre la salud pública y los sistemas privados de salud. Entre esos dos polos, o en su combinación, se debate la situación actual.

\section{LOS CAMINOS QUE SE VISLUMBRAN Y LAS ENSEÑANZAS}

En 1997 hubo una reunión privada auspiciada por el World Business Council on Sustainable Development y la presidencia de la Asamblea General de la ONU, donde 37 participantes - la mayoría representantes de corporaciones - fueron invitados a discutir las posibilidades de acuerdos multipartidarios en la orientación de los fondos de las Naciones Unidas. Este fue el bautismo formal de lo que hoy en día son decenas de Private-Public Partnerships (PPP) (Korten, 1997) ${ }^{26}$. Un año después, el Banco Mundial y la Organización Mundial de la Salud anunciaban un llamamiento a este tipo de acuerdos (Reich, 2002). Las PPP son organizaciones sin fines de lucro que reúnen a las ONG, a miembros de la sociedad civil (académicos, por ejemplo), a instituciones filantrópicas, a instituciones públicas nacionales e internacionales y a las empresas farmacéuticas. Es un mecanismo de coordinación de investigación y desarrollo, así como de obtención de fondos. El objetivo es reducir la desigualdad en salud, fomentando la investigación en áreas poco lucrativas, y facilitando el acceso de vacunas y medicinas a pueblos sin el poder adquisitivo necesario.

¿Por qué la necesidad de estos acuerdos? La globalización trae consigo una fuerte concentración de la riqueza. Varias corporaciones transnacionales tienen ventas anuales superiores al producto interno de cientos de países. Para ellas, los organismos internacionales que recogen fondos de los gobiernos son espacios demasiado democráticos de decisión. La presión de estas corporaciones sobre los

\footnotetext{
26 "Para examinar pasos hacia el establecimiento de referencias para la participación del sector empresarial en el proceso de establecer políticas de las Naciones Unidas y asociándose en los usos de los fondos de asistencia al desarrollo de las Naciones Unidas" (Korten, 1997).
} 
gobiernos ha llevado a retirar o demorar el aporte de los fondos y la consecuente crisis financiera de, por ejemplo, las Naciones Unidas y sus diversos sectores. Una vez creado el problema, el apoyo de grandes empresas se convierte en elemento de sobrevivencia para las instituciones. El PPP, que se formó con el Global Alliance for Vaccines and Immunization (GAVI) en 1999, no hubiese surgido de no ser por el aporte inicial de la Fundación Gates con 750 millones de dólares, mayor que los posteriores aportes de la OMS y otros países y fundaciones.

También existe el dogma de que el mercado es el único camino para solucionar todo tipo de problema. Cuando algo no corresponde con las expectativas, como en el caso de la salud, se trata de una falla del mercado. Frente a este problema los economistas ortodoxos no encuentran más que dos alternativas: pull o push. La primera consiste en incentivar la producción, la segunda en incentivar las compras. Ambas alternativas mediante subsidios y donaciones que sólo pueden provenir, según ese razonamiento, de quienes tienen, o sea, las corporaciones. Además, si las organizaciones públicas internacionales no participan quedan "fuera de la jugada", ya que las corporaciones pueden perfectamente lanzar acuerdos multilaterales con gobiernos y entre empresas, con impactos mayores que los programas de estas instituciones internacionales. Pero, por otra parte, a las corporaciones les interesa que las Naciones Unidas y el Banco Mundial aparezcan como asociados: eso les da un aspecto de imparcialidad muy importante.

Otro argumento, muy utilizado en los medios académicos, es considerar a las enfermedades como una causa de la falta de desarrollo (Sachs, s/f). Ellos argumentan que para la mayoría de los países africanos al sur del Sahara, las epidemias de SIDA o malaria son un impedimento para el desarrollo de los países, y que su inmediato tratamiento impulsaría dichos pueblos al desarrollo. Esta interpretación parte de tres supuestos relacionados. El primero es que no existe una relación causal entre pobreza y enfermedad, sino que la cura de la enfermedad puede conducir a la salida de la pobreza ${ }^{27}$. El segundo es que la única forma de solucionar el problema es a través de mecanismos de mercado que respeten los derechos de patente. Así, serían las corporaciones farmacéuticas las encargadas de la producción y el problema estaría en la falta de mercado interno, que debería de ser substituido

\footnotetext{
${ }^{27}$ La hipótesis de que la enfermedad es el impedimento al desarrollo fue puesta a prueba por Brown en la isla de Cerdeña. Después de la Segunda Guerra Mundial la Fundación Rockefeller implementó una exitosa campaña para erradicar el mosquito trasmisor de la malaria. Pero el esperado desarrollo económico no se materializó. Brown estimó que la malaria consume 4,6 \% de las calorías en la víctima, sin embargo el macroparasitismo de los terratenientes consume, en forma de renta, $62 \%$ de las calorías. Con ello muestra que las relaciones de producción, y no la enfermedad, determinan la pobreza . Y agrega: "Cuando llegué a Cerdeña por primera vez en 1976, expliqué a los campesinos todo sobre la hipótesis de que la malaria impide el desarrollo, y que quería estudiar los efectos económicos positivos de la erradicación de la malaria" “...la mayoría de los campesinos se rieron abiertamente de ese argumento. Para ellos, los problemas económicos de
} 
por donaciones, que sólo podrían venir de esas PPP. Éstas no tendrían las trabas burocráticas de los grandes organismos internacionales, y podrían resultar más eficaces en atender los problemas para los cuales fueron creadas. Aunque habría que decir, en contra de este último argumento, que las negociaciones entre la Organización Mundial de la Salud y las empresas farmacéuticas comenzaron en 1991, y para finales de 2002 sólo se llegó al acuerdo de subsidios en unos pocos países africanos; en el ínterin, otros países (Tailandia, India, China, Brasil, etc.) desarrollaron sus propios genéricos, un camino mucho más rápido que las negociaciones entre las compañías farmacéuticas que compiten entre ellas, y por eso tienen grandes contradicciones internas, y los organismos internacionales que pretenden seguir - al menos públicamente - controlando las PPP.

En el área de la salud, muchas de estas PPP surgieron como resultado de la lucha por el mercado y los derechos de propiedad intelectual. Como parte de los tratados de libre comercio de la Organización Internacional del Comercio (WTO), 123 países firmaron el Acuerdo sobre Derechos de Propiedad Intelectual (TRIPS) que entró en vigor en 1995. Ese tratado obliga a los países a respetar los periodos -20 años en los productos farmacéuticos - de derecho de propiedad. Durante ese tiempo no se pueden producir medicamentos genéricos, equivalentes a los de la marca que tienen la patente. $O$ sea, la marca tiene el monopolio durante ese periodo de tiempo. Esta ventaja explica que las transnacionales farmacéuticas presionen a los países para que establezcan en su legislación derechos de propiedad intelectual. Ya desde 1993, el gobierno de los Estados Unidos, reflejando los intereses de las trasnacionales farmacéuticas, comenzó a presionar para expandir las patentes por todo el mundo (Gellman, 2000a). Pero, debido a la epidemia del SIDA, algunos países como India, China, Tailandia o Brasil, comenzaron a producir, a fines de los noventa y principios del siglo XXI, remedios genéricos competitivos con los de marca con patente. Incluso África del Sur, tras un largo juicio en la Corte Suprema de Justicia de ese país, consiguió el aval del tribunal para producir remedios genéricos, en contra del bloque formado por 39 compañías farmacéuticas transnacionales. Con ello, el lucrativo mercado de los medicamentos para tratar el SIDA se viene abajo. Para que el lector tenga una idea, en los Estados Unidos el tratamiento cuesta hasta 15 mil dólares al año. En otros países

\footnotetext{
la isla... debían de ser localizados en la propiedad del suelo... Desde su perspectiva la malaria ha sido una consecuencia y no una causa de su pobreza... las discusiones sobre los efectos benéficos tanto sociales como económicos del control de la enfermedad y erran al no hacer la pregunta de "desarrollo para quién". Por ejemplo, la respuesta a esta pregunta en el Ceylan Británico era claramente" los dueños de las grandes plantaciones de té... Aun después de la Segunda Guerra Mundial los efectos benéficos tanto sociales como económicos del control de la malaria continúan sirviendo a los intereses de los grandes empresarios privados... con pocas ventajas para los campesinos rurales empobrecidos" (Muraskin, 2001: 107-108).
} 
desarrollados donde se respetan los derechos de patente el tratamiento no baja de los 9.000 dólares anuales. Pero Brasil ya está produciendo los medicamentos por menos de 3.000 dólares anuales, y la India los ofrece a 300. Como señaló la representante de la industria farmacéutica de África del Sur después del fallo en su contra de la justicia, el problema es de precedente: "mientras Sudáfrica puede representar menos de un $1 \%$ de las ventas de medicinas, el precedente de permitir a un gobierno que pise los derechos de patente de las compañías tendrá efectos de mayor alcance que las cuestiones de costos y crisis" (Block, 2001). La declaración de emergencia sanitaria de un país, y la posibilidad de emitir licencias obligatorias para producir remedios genéricos se puede expandir como la pólvora, con lo que las compañías farmacéuticas perderían millones de dólares. Entonces, se embarcaron en la creación de PPP con el propósito de contrarrestar tales iniciativas.

El banco de datos de la Initiative on Public-Private Partnerships for Health tenía registrados, para finales del año 2002, 79 PPP (IPPPH, 2002) que respondían a los más diversos criterios de formación, participación y tomada de decisiones. La Internacional AIDS Vaccine Initiative (IAVI), fundada en 1996, es una PPP que pretende acelerar el desarrollo de vacunas contra el HIV/AIDS. La Global Alliance for Vaccines and Immunization (GAVI), fundada en 1999 tiene el propósito de facilitar la inmunización de los niños de los países pobres, así como estimular a la industria farmacéutica para el desarrollo de vacunas vitales para países pobres. Otro ejemplo es la Medicines for Malaria Venture (MMV), también fundada en 1999 como resultado de conversaciones entre la Organización Mundial de la Salud y la Federación Internacional de las Asociaciones de Productores Farmacéuticos (IFPMA) y con el propósito de desarrollar vacunas contra la malaria.

Todo este tipo de asociaciones es presentado como una propuesta win-win. Todos ganan: los enfermos, los organismos internacionales, las empresas farmacéuticas. Pero, esta visión algo romántica esconde las importantes diferencias de intereses entre los actores en juego. El interés de las empresas es siempre la ganancia. Y la ganancia se logra produciendo medicinas para personas enfermas. Es mejor un pueblo enfermo que tenga poder adquisitivo, a uno sano. Es mucho más rentable producir medicinas para tratamientos de larga duración que vacunas que se aplican pocas veces en la vida de las personas. Es por eso que el mercado de las vacunas no representa más que el $2 \%$ de las ventas de las compañías farmacéuticas. La declaración de un alto dirigente de una empresa farmacéutica respecto del SIDA es elocuente respecto de estos intereses: "lo mejor de las drogas contra el SIDA es que hay que tomarlas de por vida" (Gellman, 2000b).

Por el contrario, el interés de la salud pública es que la gente esté sana y no enferma. Cuantas menos medicinas tenga que tomar la población y menos atención médica, mejor. Es evidente que estamos hablando de dos agentes con intereses diametralmente opuestos. Cómo pueden estas asociaciones alcanzar resultados óptimos para ambas partes es realmente dificil de concebir. Esto ha desatado 
RIS

REVISTA INTERNACIONAL DE SOCIOLOCIA

№ 34, Enero - Abril, 2003

CUILLERMO FOLADOR

muchas críticas y reclamaciones (Horton, 2002; Boseley, 2002; Hardon, 2001; Hancock, 1998).Y la historia de los últimos diez años muestra que bajo el velo de un exitoso camino para el desarrollo de la salud mundial se esconde la apropiación de la salud pública por la empresa privada. Esto se puede ver, claramente, con cuatro constantes que se repiten en la mayoría de las PPP de forma conjunta o combinada. La primera es la del respeto a las patentes. Las PPP son cuidadosas en garantizar este derecho. Incluso la Organización Mundial de la Salud que participa de varias de las más importantes PPP tiene una posición contraria a la fabricación de genéricos. Pero es la garantía de las patentes lo que ha encarecido los medicamentos. Es su garantía lo que hace que se investigue en enfermedades de ricos. Es su garantía lo que hace que se investigue en tratamientos de larga duración y poco en vacunas. Es su garantía, en definitiva, la que ha creado tal disparidad en la distribución de la salud en el mundo.

La segunda es la defensa de las nuevas vacunas. Como existen muchas vacunas no patentadas, las empresas farmacéuticas sólo se incorporan a las PPP si se trata de enfermedades cuyas vacunas tengan patente vigente, o que puedan ser patentadas en el futuro. Si son vacunas de enfermedades de países pobres es necesario que se trate de nuevas vacunas que puedan ser patentadas, y no de vacunas cuyas patentes ya vencieron y no ofrecen mayor lucro. Esto crea el problema de la posibilidad de que un país esté inmunizado contra una enfermedad para la que existe una vacuna reciente y deje de estar inmunizado para otras enfermedades para las que hace años existen las vacunas (Hardon, 2001).

La tercera es el mercado selectivo. Las empresas sólo se interesan por PPP que trabajen en países seleccionados, mientras se garanticen los altos precios de los medicamentos en los países desarrollados y en otros en desarrollo con amplios mercados como Brasil, México o la India. Con ello, disminuyen los precios de sus productos en algunos países africanos, colaboran junto a las donaciones y los esfuerzos de los organismos internacionales y usan dichos países como ejemplos de propaganda. Mientras tanto, millones de enfermos en otros países e incluso los pobres de los países desarrollados que no tienen acceso a los medicamentos baratos quedan por el camino.

La cuarta es su política de la doble cara. Por un lado, hacen acuerdos que aparecen en los periódicos como ejemplos de su interés humanitario. Por otro, continúan presionando a los gobiernos para que impongan sanciones a los países que emiten licencias obligatorias o producen medicamentos similares a los de patente para combatir sus epidemias. Un informe de Oxfam (2002) ilustra y cuantifica este tipo de acciones por parte de las compañías farmacéuticas sobre el representante de comercio de los Estados Unidos para que incluya sus demandas en los acuerdos de la Organización Internacional del Comercio, o establezca sanciones con los países acusados. Una carta del 25 de noviembre de 2002, firmada por 20 compañías farmacéuticas y enviada al representante comercial de los Estados Unidos es indicativo de este tipo de amenazas: "Una puerta abierta o una 
excepción que no esté muy clara a las normas de protección de patentes minaría seriamente nuestros intereses y echaría atrás los objetivos públicos a largo plazo que Doha pretendió alcanzar. Le urgimos negociar una solución que se limite específicamente a las enfermedades que fueron el foco de la Declaración de Doha, esto es, SIDA, tuberculosis, malaria y otras enfermedades epidémicas de similar escala. Además, debe quedar claro que sólo países del Sahara Africano, realmente en desventaja, deben ser los receptores del cambio de reglas" (Loff, 2002b).

Existe, por otra parte, toda una moderna ideología que presiona desde dentro de las empresas para mejorar su imagen internacional, en especial en cuestiones como medio ambiente, salud de los trabajadores, minorías, relaciones de género, y salud en general. En el tema del medio ambiente, por ejemplo, las grandes empresas hacen importantes esfuerzos por "enverdecerse" y las industrias más avanzadas tecnológicamente utilizan sus mayores controles y políticas "verdes" para competir ventajosamente en el mercado ${ }^{28}$. Las frecuentes donaciones de las transnacionales de la farmacia a los países pobres son parte de esta política de imagen frente al consumidor. La empresa de inversiones (Calvert, 2002), por ejemplo, basan su plan de inversiones en requisitos sociales que las empresas deben cumplir (lugar de trabajo, medio ambiente, derechos indígenas, etc.) y tiene entre su lista de empresas varias farmacéuticas de gran porte. Es probable que en un futuro cercano, se sumen a esos requisitos algunos relacionados específicamente con el compromiso con el salud pública.

Frente a estas novedades se puede concluir que la crisis de la salud ha dejado, por lo menos, tres grandes enseñanzas.

a) La primera es que la industria farmacéutica se regula por la ganancia, por lo que no puede ser la solución para los problemas de salud del mundo. La industria farmacéutica argumenta que, gracias a ella, la humanidad ha elevado su esperanza y mejorado la calidad de vida. Sin embargo, no existen reduccionismos en materia de salud. Como ya ha sido señalado, hay notorias evidencias de que el aumento del nivel de vida en general - con independencia de las políticas de salud - conduce a una disminución de las enfermedades y aumenta la esperanza de vida. Esto no significa que la industria farmacéutica no tenga un importante papel. Pero esto es relativo, y está subordinado al contexto general en que se aplican sus medicamentos. En un contexto de globalización de la pobreza no hay medicina, por sí sola, que solucione. Pero, tampoco es mérito alguno que la

${ }^{28} \mathrm{La}$ transnacionales de la industria química, tal vez la más contaminante del mundo, establecieron una política de "exportar ambientalismo" hacia el Tercer Mundo, consiguiendo elevar las regulaciones nacionales y limitando la competencia de las empresas locales (García-Johnson, 2000). La preocupación por certificaciones "verdes" es parte de toda una nueva cultural empresarial que debe convencer al consumidor y las ONG de su común interés (Gereffi, García-Johnson, Sasser, 2001). 
industria farmacéutica haya hecho importantes avances. Se trata del resultado obvio de una industria que para poder obtener ganancias tiene que producir alguna cosa útil. De la misma forma que no es una virtud de la industria aero-espacial que las personas se desplacen más rápido. La cuestión no está en lo que hacen, sino en lo que dejan de hacer. El problema es que la salud es considerada por la humanidad como parte de los derechos humanos. Y depositar la satisfacción de los derechos humanos en el mercado ha demostrado su ineficiencia. La industria farmacéutica no investiga en enfermedades cuyos portadores no constituyen un mercado importante, y anteponen los intereses de mercado - como corresponde a cualquier empresa - al sufrimiento de millones de personas. Muchos consideran que es hora de que la industria farmacéutica sea supervisada, reglamentada y controlada por los gobiernos o por consejos externos. No obstante, eso ya ha demostrado su dificultad en procesos donde la industria farmacéutica participa, como en mecanismos administrativos de certificación de medicamentos, registro o mantenimiento de patentes, publicación de artículos, lobby para que los gobiernos actúen internacionalmente en su favor, ocultamiento de información, etc. (Dukes, 2002; Henry \& Lexchin, 2002; Montaner et al., 2001; Barret, 2001; Galeria, 2001; Angell, 2000). Cuando, por el contrario, las movilizaciones populares han presionado para que los gobiernos busquen formas menos mercantiles de atender sus problemas de salud, el resultado ha sido notorio y mucho más rápido, como en el caso de la producción de genéricos para combatir el SIDA en Brasil, India, Tailandia, China y otros.

b) La segunda es que la producción pública de medicamentos y la lucha contra los derechos de propiedad han mostrado su eficacia relativa, como alternativa contrapuesta al mercado, para solucionar los problemas de salud. Y, lo que es más importante, que este camino sólo se alcanza mediante la movilización social. El caso del SIDA es el más ilustrativo, y Brasil un ejemplo elocuente. Antes de 1996, las invenciones y desarrollo de medicamentos no podían ser patentados en Brasil. En 1996, bajo presión de los Estados Unidos, y como resultado del surgimiento de la Organización Internacional del Comercio, el gobierno brasileño aprueba una ley de patentes para los productos farmacéuticos. En 2001 bajo presión de la sociedad civil y las organizaciones de enfermos quiebra el acuerdo internacional de patentes y libera la producción de medicamentos genéricos competitivos con los de marca importados para atender los enfermos de SIDA (Donnelly, 2001; Harrington, 2000). Brasil venía produciendo copias de drogas no patentadas desde 1998, y para 2001 consiguió producir la totalidad del componente del cóctel necesario para el tratamiento del SIDA. El resultado ha sido múltiple. Por un lado, el desarrollo de una capacidad nacional para producir algunas de las drogas que antes eran importadas, con la disminución de la dependencia tecnológica. Por otro, un fuerte descenso de los precios, tanto porque los genéricos son mas baratos (hasta 5 o 6 veces menos) que los importados, como porque transnacionales como la Merck 
acordaron, como resultado, bajar el precio de sus medicamentos entre un $65 \%$ y un 59\% (Indinavir y Efavirenz respectivamente). De 1996 a 2001 el tratamiento del SIDA disminuyó un $73 \%$ en su costo, con tendencias decrecientes, según el Ministerio de Salud (Vakhovskiy, 2001). También porque la producción nacional significó una reducción del presupuesto necesario y economía de divisas. Luego, porque esa disminución de los precios permite ampliar la atención a más pacientes. Por último, porque Brasil puede comenzar a vender sus propios medicamentos a terceros países que no tengan leyes de patentes para el caso o emitan licencias obligatorias. En Brasil se dio todo lo contrario de lo que argumentan los defensores del libre mercado y de los derechos de propiedad intelectual: en lugar de que el régimen de patentes atrajera capitales, desarrollara la industria nacional, abaratara los productos y atendiera mejor a la población, todo eso fue resultado de la quiebra de los acuerdos internacionales de patentes (Bermúdez et al., 2002). Este éxito debe contrastarse con el largo sufrimiento de África del Sur, que buscó el camino de la negociación con las transnacionales farmacéuticas (Treatment Action Campaign). Pero la eficacia de la producción estatal es relativa. La presión de las transnacionales de la farmacia y de los países desarrollados que las apoyan siempre está presente. Además, no es lo mismo producir el medicamento a que éste llegue al usuario. Para esto se necesitan mecanismos de control por parte de la población. Bajo fuertes movilizaciones es posible avances significativos, pero una vez que las reclamaciones cívicas disminuyen pueden esperarse retrocesos en las políticas públicas. Hacen falta mecanismos de vigilancia permanentes. En el área del medio ambiente las certificaciones hechas por terceras partes son tibios intentos de control de la producción por parte de los consumidores. Es probable que comiencen a surgir mecanismos semejantes en el área de la salud y la producción de medicamentos. Como organizaciones de médicos o terceras partes que vigilen las acciones de las empresas farmacéuticas en materia de investigación y desarrollo, o en precios, etc.

c) La tercera enseñanza es que el proceso de globalización no debe ser entendido exclusivamente en términos de las leyes económicas capitalistas, sino que los acuerdos de base humanitaria representan un camino mucho más sólido para solucionar los problemas de salud. Las transnacionales farmacéuticas, así como la posición de los gobiernos de los países desarrollados en el tema de los medicamentos, consideran la globalización exclusivamente desde el punto de vista económico y de las leyes del mercado. En la actualidad está habiendo una dura discusión sobre la implementación de la declaración de Doha en la Organización Internacional del Comercio. Los países desarrollados, encabezados por los Estados Unidos y la Unión Europea, pero no sin la participación activa de Canadá, Japón, Suiza y otros están desempeñando el papel de defensores de los intereses de las trasnacionales farmacéuticas contra los más elementales derechos de salud de los países pobres. Cualquier oposición a los acuerdos de la Organización Internacional 


\section{RIS}

del Comercio es vista como un atentado a la globalización. Pero varias ONG ya han planteado una visión mucho más amplia del proceso de globalización. La Treatment Action Campaign, por ejemplo, argumenta que la globalización de los derechos humanos, un acuerdo firmado en 1948 por más de 140 países, es más amplia y deber considerarse jerárquicamente superior a un acuerdo restringido a la esfera del comercio de determinados productos. La declaración garantiza, entre otras cosas, la atención médica ${ }^{29}$.

Los próximos años serán decisivos en el reacomodo de las fuerzas políticas, y esto tendrá impactos importantes en millones de personas enfermas y en las futuras generaciones. El resultado es aún incierto, pero dos alternativas - no necesariamente contrapuestas - se presentan. Por un lado, la representada por los voceros de los países desarrollados y organismos internacionales, que buscan acuerdos multipartidarios donde se mantenga la hegemonía del mercado y de las grandes empresas farmacéuticas en su control. Por otro, la representada por las ONG y los movimientos que representan los intereses de los enfermos, que buscan darle independencia de decisión a los países para atender sus problemas de salud, y colocan criterios humanitarios por delante de los intereses económicos.

\section{CONCLUSIONES}

Hace más o menos una década que la humanidad está sufriendo una clara lucha social, manifiesta en un tema de vital importancia: la salud de millones de enfermos que no tienen acceso a medicamentos adecuados, sea por la falta de recursos económicos, sea por la falta de medicamentos para atender sus enfermedades o más comúnmente por ambas razones.

El papel de la CT es crucial en esta lucha. Todos los bandos reconocen que no se investiga, o no se investiga suficientemente, o no se culminan las investigaciones en aquellas enfermedades cuyos portadores no tienen poder de compra de medicinas. Esta es una clara demostración de que la $\mathrm{CT}$ en materia de producción de medicinas no se destina a satisfacer las necesidades de la mayoría de los enfermos del mundo, sino solamente de los países y sectores más ricos.

Esta contradicción ha llevado a movilizaciones populares y a la formación de ONG que defienden los intereses de los enfermos. Pero también a una fuerte reacción por parte de las principales industrias farmacéuticas y los gobiernos de los países desarrollados. De un problema sectorial de salud, se ha transformado

\footnotetext{
29"Artículo 25.1. "Toda persona tiene derecho a un nivel de vida adecuado que le asegure, así como a su familia, las salud y el bienestar, y en especial la alimentación, el vestido, la vivienda, la asistencia médica y los servicios sociales necesarios; tiene asimismo derecho a los seguros en caso de desempleo, enfermedad, invalidez, viudez, vejez u otros casos de pérdida de sus medios de subsistencia por circunstancias independientes de su voluntad" (UN, 1948).
} 
en un problema global de disputa entre los derechos de los países ricos y pobres, $\mathrm{y}$, dentro de estos, de las clases que se ven perjudicadas y beneficiadas por tales conflictos.

La búsqueda de una solución está en la mesa de negociaciones. Es una necesidad imperiosa, tanto porque la gravedad lo ha transformado en un problema de seguridad pública, como porque su expansión en los países con epidemias imposibilita la propia reproducción del capital en determinadas áreas, y conduce a reclamaciones de varios sectores capitalistas. Además, el tráfico mercantil y de personas, el calentamiento global, y la posibilidad de acciones terroristas están preocupando a los servicios de salud de los países desarrollados. Se suma a esto el hecho de que los sistemas públicos de salud en los países desarrollados están en quiebra, y la reclamación de los ciudadanos tiene un impacto decisivo en las elecciones políticas, sobre todo el sector de tercera edad que consume más medicamentos y más rápidamente crece en la pirámide demográfica de esos países.

Las Naciones Unidas, la Organización Mundial de la Salud o los gobiernos de los países desarrollados están buscando soluciones que suponen que las principales transnacionales farmacéuticas continúen detentando el control de la ciencia y la tecnología. A este camino se llegaría si las transnacionales de la farmacia, junto con instituciones como Naciones Unidas, Banco Mundial, y otras, deciden formar un gran fondo económico basado en donaciones para producir drogas para las principales enfermedades infecciosas de los países tropicales y a precios baratos. Ello sería un subsidio directo para las transnacionales farmacéuticas y les garantizaría los derechos de propiedad intelectual. El problema es que este camino es muy lento. Las negociaciones entre la industria farmacéutica y la Organización Mundial de la Salud comenzaron en 1991 en el caso del SIDA. Después de 10 años nada se ha avanzado por ese camino, más allá de grandilocuentes declaraciones.

La experiencia de una década ya ha mostrado que el mejor camino para superar la distancia entre investigación y desarrollo de medicamentos y las necesidades sociales de los pobres es la autonomía de los países en materia de producción de medicamentos. Varios países del Tercer Mundo tienen ya una infraestructura que les permite producir copias de medicamentos patentados en amplia escala y desarrollar investigación orientada a la satisfacción de las necesidades de su población si existe una política pública determinante. También los convenios internacionales entre países pobres pueden fácilmente actualizar sus requerimientos de $\mathrm{CT}$. El sector público deberá tener, dentro de esta alterativa, un peso fundamental. Difícilmente podrá lograrse la producción de medicamentos para satisfacer las necesidades sociales por la vía del mercado. Todo parece indicar que siendo el mercado el causante de tanta injusticia, deberá recaer en manos del sector público la producción y asistencia completa a la salud de la población. Y aun así faltarán organizaciones que respondan a los consumidores para vigilar y hacer auditorias permanentes tanto de los sistemas públicos como de los privados. 
RIS

REVISTA INTERNACIONAL DE SOCIOLOCIA

№ 34, Enero - Abril, 2003

GUILLERMO FOLADORI

\section{BIBLIOGRAFÍA}

ABRAHAM, J. (2002), "The pharmaceutical industry as a political player", The Lancet, vol. 360 , Issue 9344, November, pp. 1498-1502.

ARMSTRONG, D. y C. FORELLE (2002), "Drugs officials may have broken rules on Neurontin", The Washington Post.

ANGELL, M. (2000), “The pharmaceutical industry. To whom is it accountable?", The New England Journal of Medicine, vol. 342(25), pp. 1902-1904.

AUERBACH, J. y B. KRIMGOLD (2001), Income. Socioeconomic Status and Health: Exploring the relationships, National Policy Association.

BARRET, A. (2001), "Fifty ways to keep your patent", Business Week, http://www.spancoalition.org/ NewNews/MainNews/12.07.01M.htm.

BERMÚDEZ, J., R. EPSZTEJN, M.A. OLIVEIRA y L. HASENCLEVER (2002), Access to Drugs, the WTO TRIPS Agreement, and Patent Protection in Brazil: Trends, Perspectives, and Recommendations to Help Find our Way, MSF/DND Working Group.

BLOCK, R. (2001), "AIDS activists win skirmish in South Africa. Judge widens scope of case to detrimento of drug companies”, The Wall Street Journal, 07/03/2001.

BOSELEY, S. (2002), “Unhealthy influence”, The Guardian, 06/02/2002.

BRUNDTLAND, Gro H. (2001), "Globalisation as a force for better health", 16 March http:// www.lse.ac.uk/collections/globalDimensions/lectures/globalisationAsAForceForBetterHealth/ transcript.htm.

CALVERT (2002), www.carvertgroup.com.

CENTER FOR DISEASE, CONTROL AND PREVENTION (CDC), (2002), http://www.cdc.gov/ od/oc/media/wncount.htm.

CENTRAL INTELIGENTE AGENCY (CIA), (2000), The Global Infectious Disease Threat and its Implications for the United States, www.cia.gov/cia/publications/nie/report/nie99-17d.html.

COBERLY, J. (2000), "We Cannot Eliminate TB on One Continent. TB Crosses Borders", http: //www.hopkins-tb.org/tb_conf/tb_conf_4.html.

COLLIER, J. y I. IHEANACHO (2002) "The Pharmaceutical Industry as an informant", The Lancet, vol. 360, Issue 9343, 2 November, pp. 1405-1409.

CONNOLLY, C. (2002), "Homeland Bill Covers Smallpox Shot Liability”, U.S. Would Shield Firms, Health Workers", The Washington Post, 16/11/2002.

DONNELLY, J. (2001), "Brazil to break AIDS drug patent", Boston Globe, www.globaltreatmenta ccess.org/content/press_releases/a01/082301_BG_BRA_CL.html.

60 
DUKES, M.N.G. (2002), “Accountability of the Pharmaceutical Industry”, The Lancet, vol. 360, pp. 1682-1684.

ECONOMIST (2002), "Aids and South African business. Trategic caring”, The Economist, pp. 64, $5 / 11 / 2002$.

EVANS, R., M. BARER y T. MARMOR (eds), (1994), Why are some People Healthy and others not? The Determinants of Health of Populations, Aldine de Gruyter, Nueva York.

FARMER, P. (1996), Social Inequalities and Emerging Infectious Diseases. Emerging Infectious Diseases, vol. 2, $\mathrm{n}^{\circ} 4$, pp 259-269.

(1999), "The consumption of the poor: Tuberculosis in the Late Twentieth Century", Infections and Inequalities, www.pih.org/library/essays/consumption.html.

FEDERAL TRADE COMMISSION ON "Competition in the Pharmaceutical Marketplace: Antitrust Implications of Patent Settlements" (2001), Report presented before the Committee on the Judiciary United States Senate, Washington DC, May 24, www.ftc.gov/os/2001/05/ pharmtstmy.htm.

FORTUNE (2002), The 2002 Global 500. The World's Largest Corporations, www.fortune.com $[19 / 12 / 2002]$

GALERIA, J. (2001), Patents Ignored. Brazil puts Aids care Before Drug Profits, www.americas.org/ News/Features/200104_Brazil_AIDS_Drugs/20010401_index.asp [05/12/2002].

GARANTTINI, S. (1997), “Are me-too drugs justified?”, Journal of Nephrology, n 10, pp. 283-94, http://www.sin-italia.org/jnonline/vol10n6/garat/garat.htm [09/12/2002].

GARCÍA-JOHNSON, R. (2000), Exporting Environmentalism. U.S. Multinational Chemical Corporations in Brazil and Mexico, The MIT Press, Cambridge, Massachusetts, London, England.

GELLMAN, B. (2000a), "An unequal calculus of life and death: as millions perished in pandemic, firms debated access to drugs; players in the debate over drug availability and pricing", Washington Post, 27/12/2000.

(2000b), "A turning point that left millions behind; drug discounts benefit few while protecting pharmaceutical companies' profits series: death watch: aids, drugs and Africa $2 / 3$ ", The Washington Post, 28/12/2000.

GEREFFI, G., R. GARCÍA-JOHNSON y E. SASSER (2001), "The NGO-Industrial Complex", Foreign Policy, www.foreignpolicy.com/issue julyaug_2001/gereffi.html [19/12/2002]

GEFFEN, N. (2001), "Pharmaceutical Patents, Human Rights and the HIV/AIDS Epidemic", TAC discussion document, www.tac.org.za.

GLOBAL FORUM FOR RESEARCH HEALTH (GFRH) (2002), The 10/90 Report on Health Research 2001-2002, Global Forum for Health Research, www.globalforumhealth.org, [04/ 12/2002]. 
GRABOWSKI, H. y J. VERNON (1994), "Return to R\&D on New Drug Introductions in the 1980s", Journal of Health Economics, $\mathrm{n}^{\circ} 13$, pp. 383-406.

HANCOCK, T. (1998), “Caveat Partner: Reflections on Partnership with the Private Sector”, Health Promotion International, vol. 13, n 3, pp. 193-195.

HARDON, A. (2001), "Immunisation for all? A critical look at the first GAVI partners meeting", HAI-Lights. Hai Europe, vol. 6, n 1, www.haiweb.org/pubs/hailights/mar2001/mar01_lead.html, [30/12/2002].

HARRINGTON, M. (2000), "Brazil: What Went Right? The Global Challenge of Access to Treatment \& the Issue of Compulsory Licensing", 10th National Meeting of People Living with HIV and AIDS, Rio de Janeiro, Brazil, 3 November 2000, http://www.aidsinfonyc.org/tag/activism/ brazil.html [10/12/2002].

HENRY, D. y J. LEXCHIN (2002), “The Pharmaceutical Industry as a Medicines Provider”, The Lancet, Vol. $360, n^{\circ} 16$, pp. 1590-1595.

HORTON, R. (2002), "WHO: the casualities and compromises of renewal", The Lancet, vol. 359, May 4, pp. 1605-1611.

INITIATIVE ON PUBLIC-PRIVATE PARTNERSHIPS FOR HEALTH (IPPPH), www.ippph.org.

KETTLER, H. (2002a), "Updating the cost of a New Chemical Entity", The Office of Health Economics, www.ohe.org/updating.htm [30/11/2002].

(2002b), "Narrowing the gap. Between provision and need for medicines in developing countries", The Office of Health Economics, www.ohe.org/narrowing_the_gap.htm, [05/12/2002].

(2002c), "Consolidation and competition in the Pharmaceutical Industry", The Office of Health Economics, www.ohe.org/consolidation.htm [30/11/2002].

KORTEN, D. (1997), "The United Nations and the corporate agenda", www.globalpolicy.org/reform/ korten.htm [30/12/2002].

LANCET (2002), "Editorial”, The Lancet, vol. 360, n 9346, 23 de noviembre, www.thelancet.com, $[01 / 12 / 2002]$.

LEONHARDT, D. (2002), "Growing health care economy gives Northeast a needed boost", The New York Times, 30/12/2002.

LEWONTIN, R. y R. LEVINS (1996), "El regreso de las viejas enfermedades y el nacimiento de las nuevas”, Ecología Politica, n 12, pp. 106-112.

LOFF, B. (2002a), "World Trade Organization wrestles with access to cheap drugs solution", The Lancet, vol. 360, 23 de noviembre, pp. 1670.

(2002b), "No agreement reached in talks on access to cheap drugs", The Lancet, vol. 361. 14/ $12 / 2002$. 
LOVE, J. (2000), "How much does it cost to develop a new drug", www.cptech.org/up/health/econ/ howmuch/html [05/12/2002].

(2001), "US consumer groups respond to industry capitulation in South Africa Drug case", www.cptech.org/ip/health/sa/CPTEA04192001.html [05/12/2002].

MEDECINS SANS FRONTIERS (MSF)/DRUGS FOR NEGLECTED DISEASES WORKING GROUP (DND), (2001), Fatal Imbalance. The crisis in research and development for drugs for neglected diseases, Geneva, www.msf.org.

MINISTERIO DA SAÚDE (Brasil), (2002), National STD/AIDS Programme, Brazil, "Universal Access to Antiretroviral Therapy: The Brazilian Experience", Ministério da Saúde, Brasil.

MONTANER, J., M. O'SHAUGHNESSY y M. SCHECHTER (2001), "Industry-sponsored clinical research: a double-edged sword", The Lancet, Volume 358, Issue 9296, pp. 1893-1895.

MURASKIN, W. (2001), Vaccines for developing Economies. Who will pay?, The Albert B. Sabin Vaccines Institute, New Canaan, CT.

OXFAM (2002), "US bullying on drug patents: one year after Doha", Oxfam Briefing Paper, $\mathrm{n}^{\circ} 33$, Washington D.C.

RAMSAY, S. (2001), "No closure in sight for the 10/90 health-research gap", The Lancet, Vol. 358 issue 9290 , Oct. 20 , pp. 1348.

REDE INTERAGENCIAL DE INFORMAÇÕES PARA A SAÚDE (RIPSA) (2002), "IDB 2001 Brasil. Indicadores Demográficos e Socioeconômicos”, Ministerio da Saúde, Brasilia, DF.

REICH, M. (2002), “Public-Private Partnerships for Public Health”, In: Reich, M. (ed). 2002, PublicPrivate Patnerships for Public Health, Harvard University Press, Cambridge, Massachusetts.

ROGERS, A. (2002), "European Parliament approves pharma law overhaul”, The Lancet, vol. 360 issue 9343 , nov. 2 , pp. 1397-1398.

SACHS, J. ( s/f ) "Health spending and the poverty trap", www.dse.de/ef/web02/sahcs.htm, [19/ 12/2002].

SIMPSON, H. (2002), "Biotechnology and the Economics of Discovery in the Pharmaceutical Industry", The office of Health economics, www.ohe.org/biotechn.htm, [02/12/2002].

SUSSEX, J. y N. MARCHANT (2002), "Risk and return in the Pharmaceutical Industry", The Office of Health Economics, www.ohe.org/riskand.htm, [30/12/2002].

THEO, J. y F. DANA (1998), "Changes in the distribution of dengue transmission under climate warming scenarios", www.nal.usda.gov/ttic/tektran/data/000007/07/0000070756.html, [12/08/ 2002].

TESH, S. N. (1996), Hidden Arguments. Political Ideology and Disease Prevention Policy, Rutgers University Press, New Brunswick, New Jersey. 
RIS

REVISTA INTERNACIONAL DE SOCIOLOCIA

№ 34, Enero - Abril, 2003

GUILLERMO FOLADORI

TREATMENT ACTION CAMPAIGN (TAC), www.tac.org.za.

TROUILLER, P., E. TORREELE, P. OLLIARO, N. WHITE, S. FOSTER, D. WIRTH, y B. PÉCOUL (2001), "Drugs for neglected diseases: a failure of the market and a public health failure?", Tropical Medicine \& International Health, $\mathrm{n}^{\circ} 6$ (11), pp. 945-951.

TROUILLER, P., C. BATTISTELLA, J. PINEL y B. PECOUL (1999), "Is orphan drug status beneficial to tropical disease control? Comparison of the American and future European orphan drug acts", Tropical Medicine and International Health, vol. 4, $\mathrm{n}^{\circ}$ 6, June, pp.412-420.

TOWNSEND, M., L. KAISER, H. MELGAR-QUINONEZ, P. CRAWFORD, M. FUJII y N. FELDMAN (2002), "Food insecurity is differentially related to overweight among low-income Latina mothers and their children", [Research Project not published. Department of Nutrition.University of California-Davis].

UNITED NATIONS (UN), (1948), Declaración Universal de los Derechos Humanos, http: //www.un.org/spanish/aboutun/hrights.htm, [19/12/2002].

VAKHOVSKIY, A. (2001), "Winning the war on AIDS, Brazil Style", Dartmouth Free Press, www.uwire.com/content/topops081001001.html, [18/12/2002].

WADE, R. (2001), "The Rising Inequality of World Income Distribution", Finance \& Development, Vol. 38, $\mathrm{n}^{\circ} 4$, www.imf.org/external/pubs/ft/fandd/2001/12/wade.htm ${ }_{2}$ [08/12/2002].

WEISS, R. (2002), “West Nile's Windning Toll”, The Washington Post, 28/12/2002.

WORLD HEALTH ORGANIZATION (WHO) (2002), World Health Report 2002, www.who.org.

ZUMLA, A. (2002), "Reflexion \& Reaction", -correspondence- The Lancet, Vol. 2, n', pp. 393. 